\title{
THE INFLUENCE OF TEMPERATURE CHANGES ON THE EIGEN - FREQUENCIES AND MODE SHAPES FOR RECTANGULAR PLATES CLAMPED ON THE CONTOUR
}

\author{
Cornel HAȚIEGAN, Gilbert Rainer GILLICH, Gheorghe POPOVICI, \\ Luminita (BARBONI) HAȚIEGAN \\ "Eftimie Murgu” University of Resița, Romania \\ c.hatiegan@uem.ro,gr.gillich@uem.ro,g.popovici@uem.ro, l.barboni@uem.ro
}

\begin{abstract}
The alysis of free vibrations on rectangular plates with mixed conditions of buckling in the thermal environment is carried out by means of the $3 D$ elasticity theory. In this paper there has been analyzed by the finite element method (FEM), the mode shape and the eigen-frequencies for a rectangular plate clamped on the contour for different temperatures. In this analysis successive heat degrees have been used, this fact helping to find the critical values in which the frequencies were at zero and to correlate these temperatures with the values obtained from the static analysis The temperature rise, the material graded index and the geometrical parameters on the eigen-frequencies were studied.
\end{abstract}

Keywords: temperature changes, eigen-frequencies, mode shapes, rectangular plates, FEM

\section{Introduction}

The plates are generally defined as being solids; the thickness is less than the length and respectively the width and is used in various fields as well as in engineering.[13].Thus, numerous studies in engineering focused on the study of static and dynamic behavior of the plates, being established how the deformation of these plates takes place. The dynamic behavior of the plates is defined by a few basic elements, which change their shape in particular and this leads to changes in the vibration modes and eigen frequencies [4]. The mechanic and physic characteristics of the material the plates are built off are the following [5-10]: the longitudinal elasticity module or the Young module (noted with E); the transversal elasticity module $(\mathrm{G})$; the Poisson coefficient $(v)$; the density $(\rho)$. The minimal values of these parameters for steel plates are given in table 1 :
Tab. 1 The mechanic and physic characteristics

\begin{tabular}{|c|c|c|}
\multicolumn{2}{|c|}{ of plates } \\
\hline \multicolumn{2}{|c|}{ Characteristic } & Values \\
\hline \multicolumn{2}{|c|}{ The density } & $7800 \ldots 7900\left[\mathrm{~kg} / \mathrm{m}^{3}\right]$ \\
\hline \multirow{2}{*}{$\begin{array}{c}\text { The } \\
\text { elasticity } \\
\text { module }\end{array}$} & Longitudinal & $2.1 \times 10^{10}\left[\mathrm{~N} / \mathrm{m}^{2}\right]$ \\
\cline { 2 - 3 } & Transversal & $(7.36 \ldots 7.93)^{*} 10^{10}\left[\mathrm{~N} / \mathrm{m}^{2}\right]$ \\
\hline \multicolumn{2}{|c|}{ The Poisson coefficent } & $0.27-0.30[-]$ \\
\hline
\end{tabular}

The relation existing between these parameters [11]:

$$
G=\frac{E}{2(1+v)}
$$

In this paper there are modally plate-shaped plates, whose is propping is done by clamped edges on all sides. The results from the simulation tables and charts, highlighting the influence of temperature changes of their eigen frequency and vibration modes are shown.

1.1 The modal analysis of plates having different temperatures

The chosen method for the modal analysis 
is the finite element method (FEM) using the SolidWorksprogram in the Geometry module.The 3D model used for the 42 cases, is a thin rectangular elastic plates with the sizes of $1000 \times 500 \times 2$ [mm]for length, width and respectively thickness.

In the modal analysis of the plates at different temperatures, for obtaining the eigen frequencies and the vibration modes, one has used the static analysis module und the action of its own weight[12-14]: the stages for the modal analysis are; creating the plates geometry; creating the thermal analysis study respectively the frequency type; choosing the material; applying the restraints (figure 1); discretion of finite elements (figure 2); running the modal analysis calculation; visualizing the results.

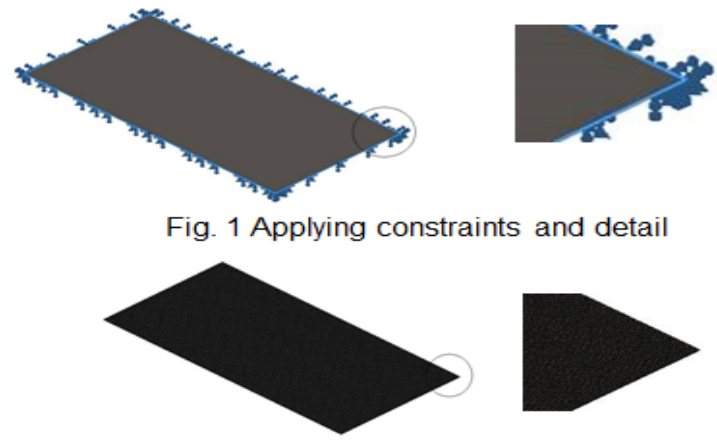

Fig. 2 Discretion of finite elements and detail Following the simulation, there were determined the first 30 mode shapes for the 42 cases examined. The mesh 3D model was made with tetrahedral finite elements of the finite element with an average size of $2 \mathrm{~mm}$, and the material used in the database of the program was the 1.023 Carbon Steel, the mechanical properties being shown in table 2:

Tab. 2 The material properties for the 1.023 Carbon Steel

\begin{tabular}{|c|c|c|c|}
\hline $\begin{array}{c}\text { Elastic } \\
\text { Modulus }\end{array}$ & $\begin{array}{c}\text { Shear } \\
\text { Modulus }\end{array}$ & $\begin{array}{c}\text { Mass } \\
\text { Density }\end{array}$ & $\begin{array}{c}\text { Poisson's } \\
\text { Coefficient }\end{array}$ \\
\hline $\begin{array}{c}2 \\
{[\mathrm{~N} / \mathrm{mm}]}\end{array}$ & $\begin{array}{c}{ }^{2} \\
{[\mathrm{~N} / \mathrm{mm}]}\end{array}$ & $\begin{array}{c}\mathrm{kg} / \mathrm{m}] \\
{[-]}\end{array}$ \\
\hline 205000 & 80000 & 7858 & 0.29 \\
\hline
\end{tabular}

Mesh in finite elements has been done by the "Solid mesh" option, using the following options: High for Mesh Quality, Solid mesh for Mesh type, Curvature based mesh for Mesher Used [15-17].The 42 cases, represent 42 different values of temperature and are: $-50,-45,-40,-35,-30$,
$-25,-20,-15,-10,-5,0,5,10,15,20,21$, $22,23,24,24.85,25,26,27,28,29,30,31$, $32,33,34,35,40,45,50,55,60,65,70$, $75,100,500$ şi $1400\left[{ }^{\circ} \mathrm{C}\right]$.

Of these positive and negative values of temperature, in table 6 , there is summarized the mesh only the plate having a temperature of 24.85 (reference temperature), and in figure 3 there is show the vibration mode shapes.

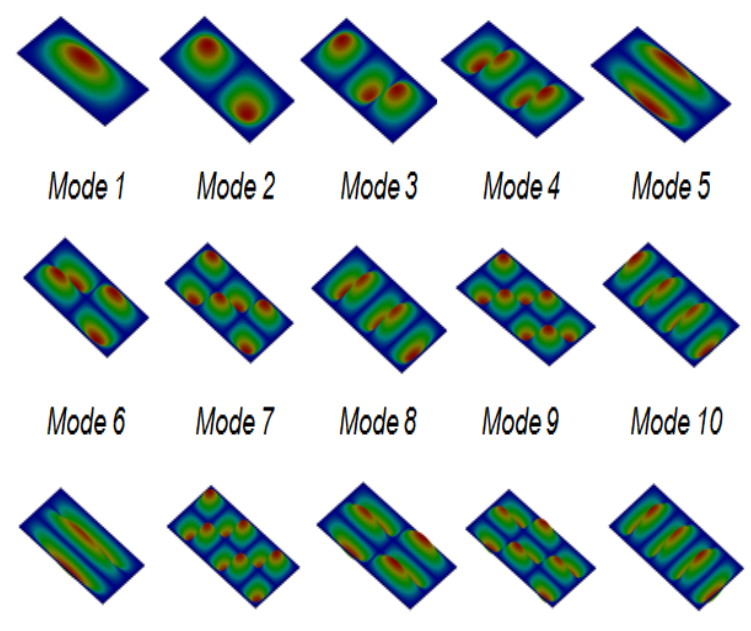

Mode 11 Mode 12 Mode 13 Mode 14 Mode 15
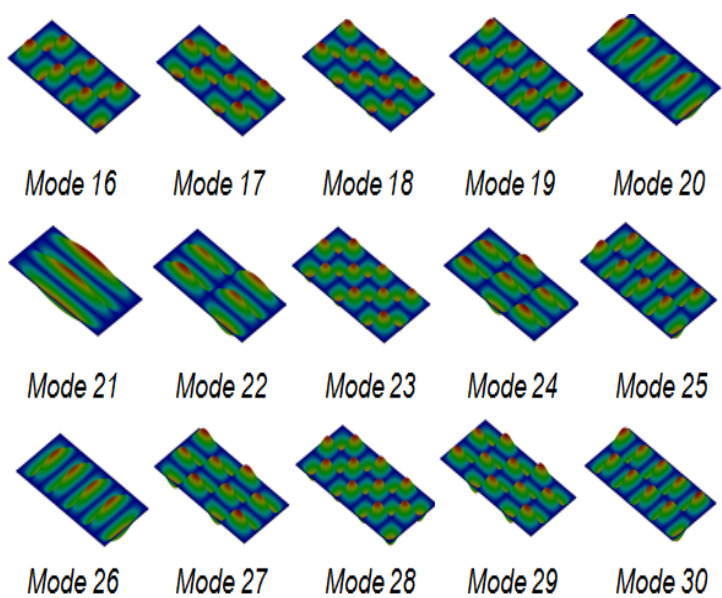

Fig. 3 Mode shapes for the rectangular plate

\section{Plates simuation results}

The results obtained by FEM for the eigen frequencies according to the rectangular plate vibration modes at the temperature of $1400 \div-50^{\circ} \mathrm{C}$, are numerically presented in table $3 \div 6$. Also, for the other 42 cases, one has obtained certain eigen frequencies values.

These results are graphically presented in 
figure 4 to 15 , as follow:

Table 3(eigen frequencies according to the rectangular plate vibration modes at the $1400 \div 55^{\circ} \mathrm{C}$ )

\begin{tabular}{|c|c|c|c|c|c|c|c|c|c|c|}
\hline Mode & 1400 & 500 & 100 & 75 & 60 & 70 & 65 & 55 & 45 & 50 \\
\hline 1 & 1840.6 & 1301.5 & 461.24 & 387.48 & 301.7 & 363.25 & 323.12 & 285.18 & 209.26 & 248.08 \\
\hline 2 & 1833.9 & 1273.1 & 458.88 & 384.7 & 298.78 & 357.47 & 312.77 & 281.73 & 208.1 & 247.42 \\
\hline 3 & 1818.1 & 1260.5 & 450.39 & 379.4 & 298.18 & 346.58 & 309.59 & 274.2 & 201.07 & 244.15 \\
\hline 4 & 1767.3 & 1177.9 & 437.32 & 374.67 & 294.69 & 339.98 & 309.19 & 258.32 & 200.8 & 243.94 \\
\hline 5 & 1734.5 & 1123.2 & 433.81 & 348.35 & 284.39 & 335.1 & 307.32 & 250.32 & 189.9 & 243.04 \\
\hline 6 & 1636.7 & 1081.2 & 378.31 & 326.38 & 267.79 & 333.5 & 305.48 & 240.32 & 188.97 & 241.83 \\
\hline 7 & 1591.2 & 1022.7 & 339.48 & 312.32 & 258 & 332.73 & 301.06 & 233.56 & 188.88 & 240.09 \\
\hline 8 & 1496.8 & 1007.3 & 330.62 & 294.6 & 253.3 & 325.23 & 292.54 & 229.14 & 186.79 & 232.09 \\
\hline 9 & 1387.5 & 948 & 326.68 & 293.17 & 241.88 & 315.54 & 281.34 & 218.86 & 186.7 & 230.85 \\
\hline
\end{tabular}

Table4(eigen frequencies according to the rectangular plate vibration modes at the $25 \div 35^{\circ} \mathrm{C}$ )

\begin{tabular}{|c|c|c|c|c|c|c|c|c|c|c|}
\hline Mode & 25 & 24.85 & 24 & 23 & 22 & 21 & 20 & 15 & 10 & 5 \\
\hline 1 & 46.892 & 47.911 & 53.281 & 58.919 & 64.013 & 68.692 & 73.041 & 73.041 & 106.46 & 119.43 \\
\hline 2 & 60.829 & 62.036 & 68.444 & 75.235 & 81.416 & 87.124 & 92.451 & 92.451 & 133.84 & 150.03 \\
\hline 3 & 85.927 & 87.266 & 94.473 & 102.27 & 109.48 & 116.22 & 122.56 & 122.56 & 173.05 & 193.15 \\
\hline 4 & 122.05 & 123.46 & 131.17 & 139.23 & 146.41 & 153.24 & 159.75 & 159.75 & 213.56 & 235.59 \\
\hline 5 & 123.5 & 124.76 & 131.62 & 139.67 & 147.66 & 155.23 & 162.42 & 162.42 & 221.4 & 245.41 \\
\hline 6 & 137.28 & 138.59 & 145.76 & 153.75 & 161.31 & 168.51 & 175.4 & 175.4 & 232.7 & 256.3 \\
\hline 7 & 161.01 & 162.38 & 169.92 & 178.35 & 186.39 & 194.07 & 201.44 & 201.44 & 263.5 & 289.31 \\
\hline 8 & 168.67 & 170.12 & 178.14 & 187.13 & 195.69 & 203.88 & 211.74 & 211.74 & 278.03 & 305.65 \\
\hline 9 & 195.17 & 196.59 & 204.44 & 213.29 & 221.78 & 229.93 & 237.79 & 237.79 & 304.99 & 333.32 \\
\hline
\end{tabular}

Table 5 (eigen frequencies according to the rectangular plate vibration modes at the $0 \div 24.85^{\circ} \mathrm{C}$ )

\begin{tabular}{|c|c|c|c|c|c|c|c|c|c|c|}
\hline Mode & 40 & 35 & 34 & 33 & 32 & 31 & 30 & 29 & 28 & 27 \\
\hline 1 & 154.09 & 97.633 & 86.485 & 75.323 & 62.985 & 50.88 & 38.131 & 22.251 & 14.515 & 29.808 \\
\hline 2 & 152.72 & 97.093 & 85.152 & 72.959 & 61.899 & 48.984 & 35.711 & 19.336 & 25.945 & 41.202 \\
\hline 3 & 143.02 & 81.038 & 71.333 & 58.162 & 50.328 & 40.679 & 20.168 & 33.644 & 52.005 & 65.371 \\
\hline 4 & 141.91 & 78.98 & 65.758 & 58.07 & 36.093 & 30.868 & 57.165 & 74.824 & 89.053 & 101.28 \\
\hline 5 & 135.18 & 77.083 & 63.138 & 42.069 & 20.482 & 50.856 & 68.803 & 82.852 & 94.764 & 105.27 \\
\hline 6 & 134.19 & 74.802 & 58.007 & 28.629 & 41.224 & 64.779 & 81.695 & 95.578 & 107.62 & 118.38 \\
\hline 7 & 132.83 & 64.993 & 33.703 & 43.975 & 70.602 & 89.542 & 105.05 & 118.48 & 130.49 & 141.43 \\
\hline 8 & 131.98 & 62.398 & 32.451 & 45.992 & 73.284 & 93.047 & 109.35 & 123.53 & 136.24 & 147.86 \\
\hline 9 & 118.85 & 21.765 & 65.505 & 89.971 & 109.02 & 125.15 & 139.38 & 152.25 & 164.08 & 175.09 \\
\hline
\end{tabular}

Table 6 (eigen frequencies according to the rectangular plate vibration modes at the $-50 \div-5{ }^{\circ} \mathrm{C}$ )

\begin{tabular}{|c|c|l|c|c|l|c|c|c|c|c|}
\hline Mode & -50 & -45 & -40 & -30 & -25 & -20 & -15 & -10 & -5 & 0 \\
\hline 1 & 213.15 & 206.5 & 199.61 & 185.02 & 177.24 & 169.08 & 160.48 & 151.35 & 141.58 & 131.01 \\
\hline 2 & 267.81 & 259.42 & 250.75 & 232.38 & 222.59 & 212.33 & 201.51 & 190.03 & 177.77 & 164.53 \\
\hline 3 & 341.37 & 330.76 & 319.79 & 296.57 & 284.21 & 271.27 & 257.64 & 243.21 & 227.82 & 211.24 \\
\hline 4 & 401.88 & 389.87 & 377.45 & 351.22 & 337.29 & 322.72 & 307.41 & 291.24 & 274.04 & 255.6 \\
\hline 5 & 425.88 & 412.86 & 399.4 & 370.96 & 355.86 & 340.05 & 323.44 & 305.89 & 287.21 & 267.17 \\
\hline 6 & 435.47 & 422.49 & 409.08 & 380.77 & 365.74 & 350.03 & 333.52 & 316.1 & 297.6 & 277.77 \\
\hline 7 & 487.34 & 472.93 & 458.05 & 426.65 & 410 & 392.61 & 374.36 & 355.12 & 334.71 & 312.89 \\
\hline 8 & 518 & 502.53 & 486.55 & 452.85 & 434.99 & 416.33 & 396.77 & 376.14 & 354.27 & 330.89 \\
\hline 9 & 553.75 & 537.61 & 520.95 & 485.83 & 467.24 & 447.83 & 427.51 & 406.11 & 383.46 & 359.31 \\
\hline
\end{tabular}




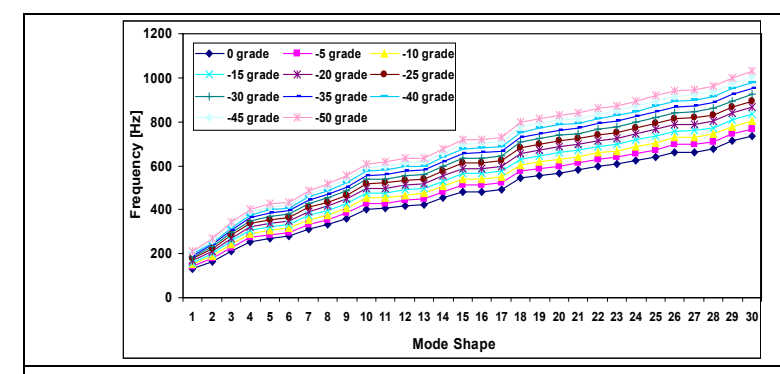

Fig. 4 The natural frequencies according to the vibration modes for negative temperatures (including $0{ }^{\circ} \mathrm{C}$ )

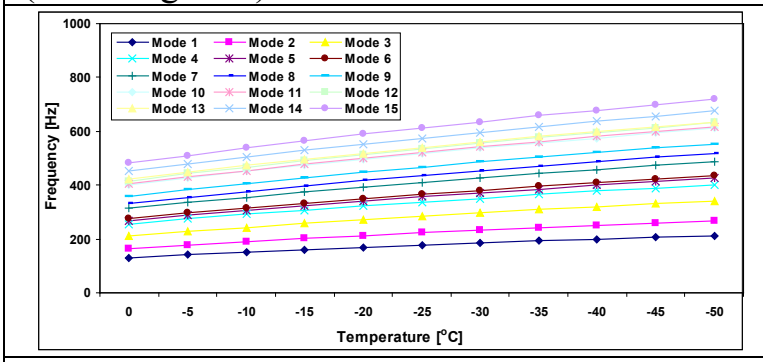

Fig. 5 The natural frequencies according to the temperatures of the vibration modes 1 to 15 for negative temperatures (including $0{ }^{\circ} \mathrm{C}$ )

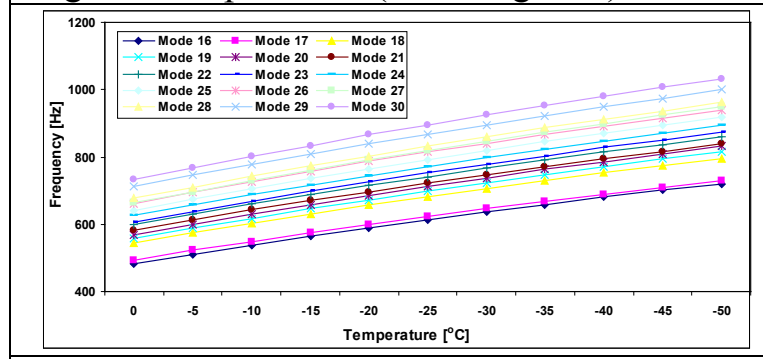

Fig. 6 The natural frequencies according to the temperatures of the vibration modes 16 to 30 for negative temperatures (including $0{ }^{\circ} \mathrm{C}$ )

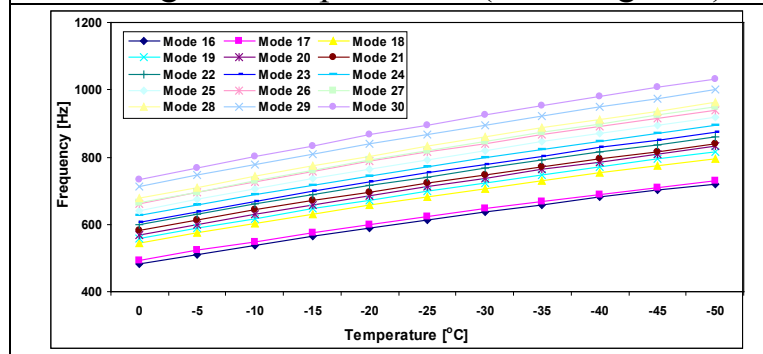

Fig. 7 The natural frequencies according to vibration modes for temperatures 5 to $25^{\circ} \mathrm{C}$

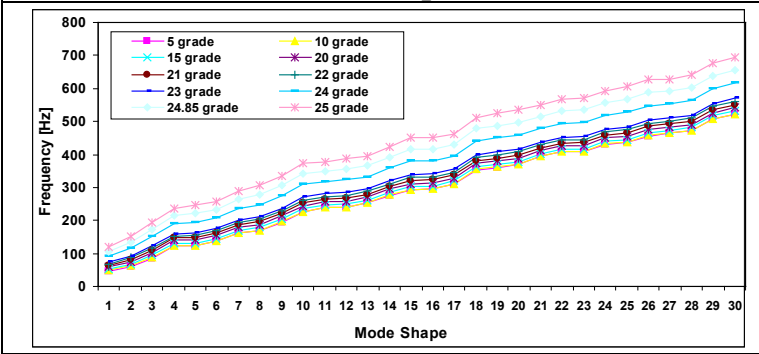

Fig. 8 The natural frequencies according to the temperatures of the vibration modes 1 to 15 for temperatures 5 to $25^{\circ} \mathrm{C}$

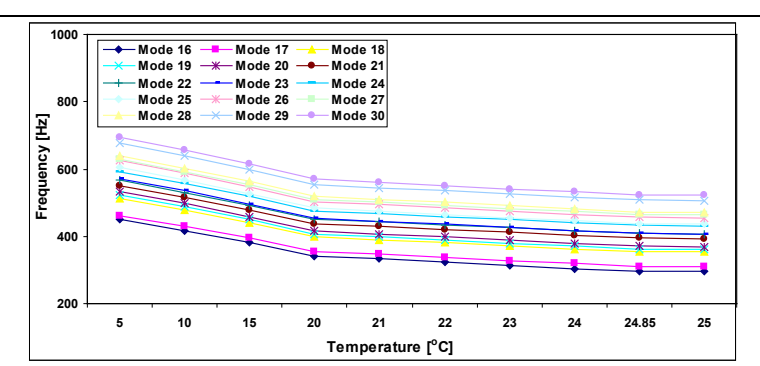

Fig. 9 The natural frequencies according to the temperatures of the vibration modes 16 to 30 for temperatures 5 to $25^{\circ} \mathrm{C}$

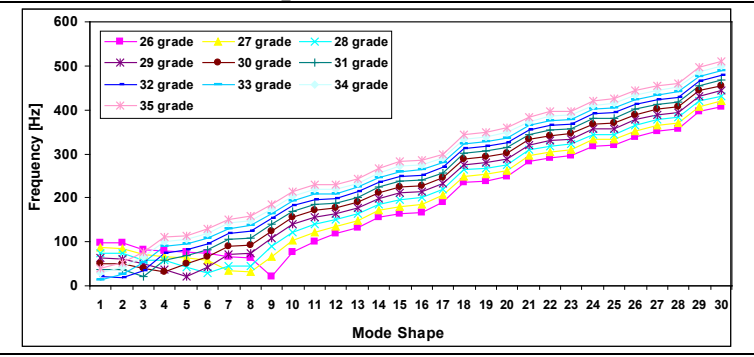

Fig. 10 The natural frequencies according to the vibration modes for temperatures 26 to $35^{\circ} \mathrm{C}$

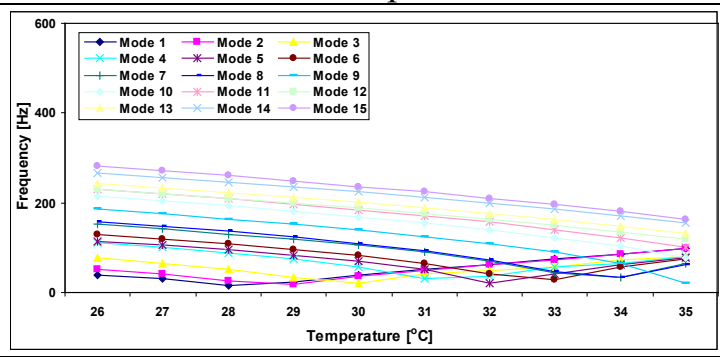

Fig. 11 The natural frequencies according to the temperatures of the vibration modes 1 to 15 for temperatures 26 to $35^{\circ} \mathrm{C}$

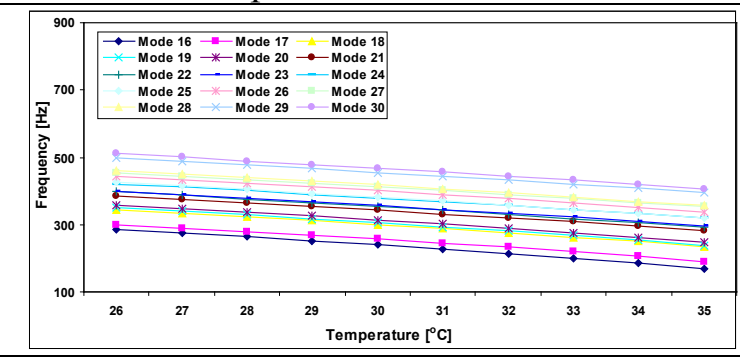

Fig. 12 The natural frequencies according to the temperatures of the vibration modes 16 to 30 for temperatures 26 to $35^{\circ} \mathrm{C}$

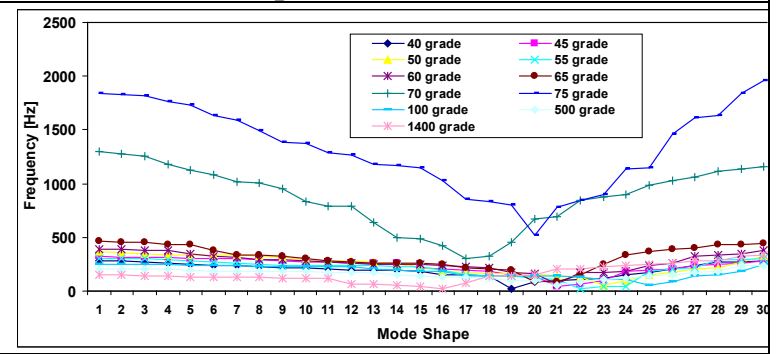

Fig. 13 The natural frequencies according to the vibration modes for high temperatures (up to $1400{ }^{\circ} \mathrm{C}$ ) 


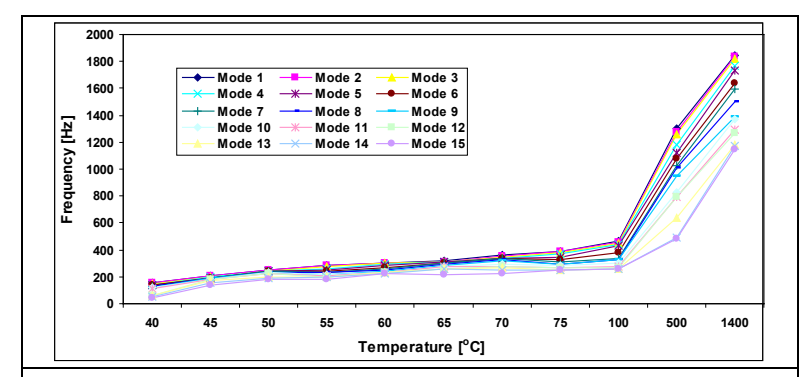

Fig. 14 The natural frequencies according to temperature of the vibration modes 1 to 15 for high temperature (up to $1400{ }^{\circ} \mathrm{C}$ )

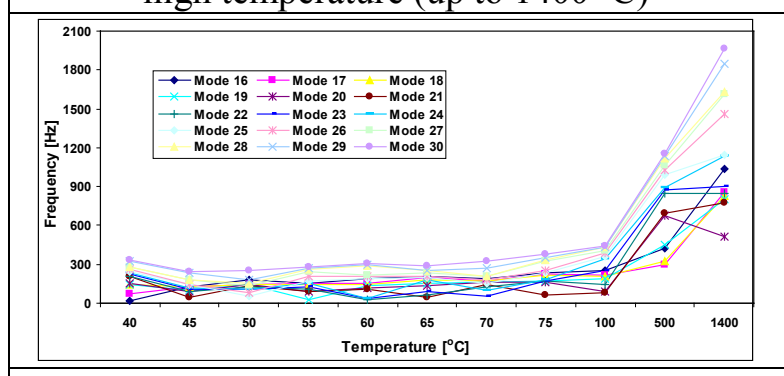

Fig. 15 The natural frequencies according to temperature of the vibration modes 16 to 30 for high temperature (up to $1400^{\circ} \mathrm{C}$ )

From the tables and graphs above, it is noted that the natural frequencies of the rectangular plate embedded in the contour fall to negative temperature to $28^{\circ} \mathrm{C}$ for mode one, $29^{\circ} \mathrm{C}$ for mode $2,30^{\circ} \mathrm{C}$ for mode 3 and so on, and then increase with the temperature.

From Tables 3 to 6 and Figures 4 to 15 it is also observed that the frequencies increase approximately linearly depending on the mode shape for negative temperatures and for positive temperatures up to the temperature of 28 the custom frequencies of the rectangular plate embedded on the contour increase approximately linearly depending on your own vibration modes.

From the $29^{\circ} \mathrm{C}$ frequencies to the first mode shape and then increase, for the over temperatures above $100^{\circ} \mathrm{C}$ have a very pronounced increase depending on the temperature.

\section{Conclusion}

The following conclusions can be drawn :

- For negative values of temperature, the eigen frequencies, and temperatures decrease linearly with an increase in the vibration modes;

- For positive temperatures, lower or near the reference temperature of $24.85^{\circ} \mathrm{C}$, the eigen frequencies decline with the increasing temperature and with their own ways;

- For temperatures higher than the reference temperature $\left(24.85^{\circ} \mathrm{C}\right)$, but up to $35^{\circ} \mathrm{C}$, the eigen frequencies for the first vibration modes, present an anomaly, i.e. decrease and then increase to certain values, which does not happen but for the ways of large vibration;

- For high temperature applied evenly on the plate, the eigen frequencies increase sharply due to the change in the material it is constructed like.

[1] Cornel Haţiegan, Edwald-Viktor Gillich, Ovidiu Vasile, Marian-Dumitru Nedeloni, Ioan Pădureanu, Finite Element Analysis of thin plates clamped on the rim of different geometric forms. Part I: Simulating the Vibration Mode Shapes and Natural Frequencies, Romanian Journal of Acoustics \& Vibration, Vol.XII, No.1, 2015.

[2] Cornel Haţiegan, Edwald-Viktor Gillich, Ovidiu Vasile, Marian-Dumitru Nedeloni, Marcel Jurcu, Petru Magheţi, Finite Element Analysis of thin plates clamped on the rim of different geometric forms. Part II: The Absolute and Relative Variation of Natural Frequencies, Romanian Journal of Acoustics \& Vibration, Vol. XII, No.1, 2015.

[3] Marius Tufoi, Cornel Haţiegan, Ovidiu Vasile, Gilbert-Rainer Gillich, Dynamic Analysis of Thin Plates with Defects by Experimental and FEM Methods, Romanian Journal of Acoustics and Vibration, Vol. X, No.2, 2013.

[4] Marius Tufoi, Gilbert-Rainer Gillich, Zeno-Iosif Praisach, Jean Loius Ntakpe, Cornel Hatiegan, An Analysis of the Dynamic Behavior of Circular Plates from a Damage Detection Perspective, Romanian Journal of Acoustics \& Vibration, Vol.X, No.1, 2014. 
[5] Marius Tufoi, Gilbert-Rainer Gillich, Ion Cornel Mituletu, Cornel Hatiegan, An Analysis of the Dynamic Behavior of Rectangular Plates from a Damage Detection Approach, Romanian Journal of Acoustics \& Vibration, Vol. XII, Nr.2, 2015.

[6] Cornel HAŢIEGAN, Gilbert-Rainer GILLICH, Mihaela RĂDUCA, Eugen RĂDUCA, Ana Maria BUDAI, Florian MUNTEAN, "Finite Element Analysys of Natural Frequencies and Mass Participation's Coefficients for Thin Plates with Defects", Scientific Bulletin of" Politehnica" University of Timisoara, Volumul 57, No. 2, 2012.

[7] Haţiegan C., Nedeloni M. D., Tufoi M., Protocsil C., Răduca M., Modal Analysis Of Natural Frequencies And Mass Participation Coefficients Of Simply Supported Thin Plates With Damages, Constanţa Maritime University Annals, Anul XIV, Volum 19, Pp. 115-120, 2013.

[8] Haţiegan C., Tufoi M., Răduca E., Protocsil C., Mituleţu C., Modal Analysis Through Solidworks Software Of Clamped Thin Plates With Damages, Constanţa Maritime University Annals, Anul XIV, Volum 19, Pp. 121-124, 2013.

[9] Haţiegan C., Gillich G. R., Gillich N., Tufoi M., Răduca M., Modal Analysis of Thin Plates with Damage Simply Supported on all Edges, Analele Universităţii "EFTIMIE MURGU", Fascicula de Inginerie, Anul XX, Nr. 1, Reşiţa, 2013.

[10] Haţiegan C., Gillich G. R., Răduca E., Nedeloni M. D., Cîndea L., Equation of Motion and Determining the Vibration Mode Shapes of a Rectangular Thin Plate Simply Supported on Contour Using MATLAB, Analele Universităţii "Eftimie Murgu", Fascicula de Inginerie, Anul XX, Nr. 1, Reşiţa, 2013.

[11] Tufoi M., Haţiegan C., Gillich G. R., Protocsil C., Negru I., Frequency Changes in Thin Rectangular Plates due to Geometrical Discontinuities. Part I: Finite Element Analysis, Analele Universităţii "EFTIMIE MURGU", Fascicula de Inginerie, Anul XX, Nr. 3, Reşiţa, 2013.

[12] Cornel Hatiegan, Marian-Dumitru Nedeloni, Cristinel Popescu, Marius Tufoi, Ioan Pădureanu, Cristian Rudolf, Comparative Study through Modal Analysis of Thin Trapeze Shape Plates Clamped on Contour without and with Damages, Analele Universităţii "Eftimie Murgu" Reşiţa, Fascicula de Inginerie, Anul XXII, Nr. 2, 2015.

[13] Marian-Dumitru Nedeloni, Cornel Haţiegan, Florian Muntean, Marcel Jurcu, Irina Maria Terfăloagă, Petru Magheţi, A Modal Analysis Study of Thin Parallelogram Plates Clamped on the Rim with and without Defects Using the Solid Works Program, Analele Universităţii "Eftimie Murgu" Reşiţa, Fascicula de Inginerie, Anul XXII, Nr. 2, 2015.

[14] S. Xiao, B. Chen, "Dynamic and buckling analysis of a thin elastic-plastic square platein a uniform temperature field", Acta Mech Sinica 21, Pp.181-186, 2005.

[15] Cornel Haţiegan, Mihaela Molnar, Sorin Trocaru, Ioan Pădureanu, Marcel Romulus Jurcu, Florin Ilie, Modeling and Simulation of Thermal Analysis of a Teflon Coated Plate, International Conference KNOWLEDGE-BASED ORGANIZATION 2016, Volume 22, Issue 3, Pages 639-643, July 2016.

[16] P.Malekzadeh, S.A.Shahpari, H.R.Ziaee, Three-dimensional free vibration of thick functionally graded annular plates in thermal environment, Journal of Sound and Vibration, Vol.329, Pp. 425-442, 2010.

[17] P. Shi, C.Y. Dong, Vibration analysis of functionally graded annular plates with mixed boundary conditions in thermal environment, Journal of Sound and Vibration, Vol.331, Pp. 3649-3662, 2012. 